\title{
Experimental Investigation of Comparative Process Capabilities of Metal and Ceramic Injection Molding for Precision Applications
}

Islam, Aminul; Giannekas, Nikolaos; Marhöfer, David Maximilian; Tosello, Guido; Hansen, Hans Nørgaard

Published in:

Journal of Micro and Nano-Manufacturing

Link to article, DOI:

$10.1115 / 1.4033820$

Publication date:

2016

Document Version

Peer reviewed version

Link back to DTU Orbit

Citation (APA):

Islam, A., Giannekas, N., Marhöfer, D. M., Tosello, G., \& Hansen, H. N. (2016). Experimental Investigation of Comparative Process Capabilities of Metal and Ceramic Injection Molding for Precision Applications. Journal of Micro and Nano-Manufacturing, 4(3), 1-9. [031003]. https://doi.org/10.1115/1.4033820

\section{General rights}

Copyright and moral rights for the publications made accessible in the public portal are retained by the authors and/or other copyright owners and it is a condition of accessing publications that users recognise and abide by the legal requirements associated with these rights.

- Users may download and print one copy of any publication from the public portal for the purpose of private study or research.

- You may not further distribute the material or use it for any profit-making activity or commercial gain

- You may freely distribute the URL identifying the publication in the public portal 


\title{
Experimental investigation of comparative process capabilities of metal and ceramic injection moulding for precision applications.
}

\author{
Islam, Aminul ${ }^{1}$ \\ Centre for Acoustic Mechanical Micro Systems, Technical University of Denmark \\ $\emptyset$ rsteds Plads, Building 352, room 018, 2800 Kgs. Lyngby \\ mais@mek.dtu.dk
}

Giannekas, Nikolaos

Department of Mechanical Engineering, Technical University of Denmark Produktionstorvet, Building 427, room 322, 2800 Kgs. Lyngby

nikgia@mek.dtu.dk

Marhöfer, David

Department of Mechanical Engineering, Technical University of Denmark Produktionstorvet, Building 427, room 314, 2800 Kgs. Lyngby maxmar@mek.dtu.dk

Tosello, Guido

Department of Mechanical Engineering, Technical University of Denmark Produktionstorvet, Building 427, room 323B, 2800 Kgs. Lyngby guto@mek.dtu.dk

Hansen, Hans

Department of Mechanical Engineering, Technical University of Denmark Produktionstorvet, Building 427, room 321A, 2800 Kgs. Lyngby hnha@mek.dtu.dk

\footnotetext{
${ }^{1}$ Corresponding author
} 
ASME - Journal for Micro and Nano-Manufacturing

\section{ABSTRACT}

The purpose of this paper is to make a comparative study on the process capabilities of the two branches of the powder injection moulding (PIM) process- metal injection moulding (MIM) and ceramic injection moulding (CIM), for high-end precision applications. The state-of-the-art literature does not make a clear comparative picture of the process capabilities of MIM and CIM. The current paper systematically characterizes the MIM and CIM processes and presents the process capabilities in terms of part shrinkage, surface replication, tolerance capability and morphological fidelity. The results and discussion presented in the paper will be useful for thorough understanding of the MIM and CIM processes and to select the right material and process for the right application or even to combine metal and ceramic materials by moulding to produce metal-ceramic hybrid components.

Keywords: metal injection moulding, ceramic injection moulding, comparative process analysis, shrinkage, surface roughness, morphology.

\section{INTRODUCTION}

Powder injection moulding (PIM) is a net-shape manufacturing process for metal and ceramic components which can combine the advantages of plastic moulding with the performance attributes of either of the materials [1]. The main difference of powder injection molding in comparison to plastic injection molding arise from the usage of the feedstocks. PIM process use metal or ceramic powders mixed with plastic binders, where the heavy powder weight compared to the lightweight polymer binder leads to a serious increase in the inertia of material flow. As a result, the powder feedstocks tend to show more jetting and wall-slip phenomena compared to the conventional plastic moulding $[2,3]$. Moreover, powder-binder separation at high shear rates can lead to the 
local variation in the melt viscosity which can influence the shrinkage and other mechanical properties of the final parts $[4,5]$.

Nevertheless, the powder injection moulding has become a reliable production technology for intricate metallic and ceramic parts today to be used in highly demanding and sophisticated application areas [6]. Both material groups have their own advantages and disadvantages in terms of shape complexity, dimensional accuracy, replication fidelity, bio-compatibility, heat resistance, corrosion etc. The particle size of the chosen powder, affects the part properties and process performance, e.g. smallest feature sizes, surface roughness, material strength etc. $[3,5,7]$. The typical average particle size for metal feedstock is in the range of $1 \mu \mathrm{m}$ to $20 \mu \mathrm{m}$ whereas the average particle size for ceramic powders is about $0.1 \mu \mathrm{m}$ to $1 \mu \mathrm{m}$. The most common materials for the metal injection moulding are stainless steels, low alloy steels and nickel alloys [8]. In case of the ceramic injection molding, zirconium oxide $\left(\mathrm{ZrO}_{2}\right)$ and aluminum oxide $\left(\mathrm{Al}_{2} \mathrm{O}_{3}\right)$ are the predominant materials $[2,3,9]$. Due to the smaller particle sizes, the ceramic injection molding can reproduce finer structural details compared to the metal injection moulding process. However, the powder particle size is still much larger compared to the polymer chains. Consequently, powder injection molding shows in general worse performance regarding reproduction accuracy, aspect ratio, and surface roughness etc. when it is compared with the plastic moulding process. A thorough literature study was made to make a comparison of PIM (MIM and CIM) with the plastic moulding process. The summary of the study is presented in Table 1. 
For applications where the requirements are high electrical or thermal conductivity and high deformability without breaking, metal is the ultimate choice. There are many examples where metals are used but ceramics can be better and cost effective alternatives due to their excellent mechanical properties, biocompatibility, corrosion, heat resistance and excellent surface finish. For example, many metallic components such as the metallic screws used for fixing bone joints (e.g. hip joints) and metal braces used for dental applications can be replaced with ceramic components with better performance such as corrosion resistance, friction resistance etc. In many ways metal (MIM) and ceramic (CIM) injection moulding are complementary processes and a better understanding of the two material classes' process capability is necessary.

By systematically combining ceramic and metal powder by two-component injection moulding process, functionally versatile components with property combinations such as electrically conductive/electrically insulating, magnetic/nonmagnetic, thermally conductive/thermally insulating or ductile/hard etc. are achievable $[10,11,12]$. In the near future it may even be possible to combine ceramic and metal in the same devices to make electrical infrastructures on the insulating and heat resistance ceramic substrates similar to Moulded Interconnect Device (MID) concept as it is done now-a-days with the two component moulding of the plastic materials [13]. To efficiently realize these types of hybrid components by combining metals and ceramics, a deep understanding about the comparative process capabilities of MIM and CIM is required. The current literature or research doesn't present a clear comparative picture of the MIM and CIM processes. Further research and thorough understanding about the 
surface replication, shrinkage behaviors and effects of the process conditions on the final part quality will make it possible to compare the two processes well and select the best one for the application or to combine two processes to make hybrid metal-ceramic components. The aim of the current paper is to experimentally characterize the shrinkage behaviors, surface replication and achievable tolerance for two comparable feedstocks of metal and ceramic to present a comparison on the process capabilities of CIM and MIM for precision applications.

\section{MATERIALS AND METHODS}

For the comparative study of ceramic and metal moulding, two different feedstocks were chosen. The material chosen for ceramic moulding experiments was Catamold TZP-A, a commercially available material from BASF. For metal injection moulding the material of choice was Catamold 316L-A, a ready-to-mould and commercially available granulate again from BASF. After sintering, this material can produce parts in austenitic stainless steel 316L [14] and Catamold TZP-A material can produce parts with polycrystalline yttria-stabilised tetragonal zirconia [15]. Fig. 1 shows the standard granulates of metal and ceramic used in the experiments. Table 2 summarizes important information and specifications of the two materials. The primary reason to choose these materials for comparison is both have the same type of binder system based on Polyacetal and exhibits similar flow behavior. The particle size (diameter) of the Catamold 316L-A is in the range of $0.5 \mu \mathrm{m}$ to $15 \mu \mathrm{m}$, whereas the Catamold TZP-A has a ceramic powder particle size within the range of $0.2 \mu \mathrm{m}$ to 0.5 
$\mu \mathrm{m}$. According to the material manufacturer, their particle size and distribution are especially formulated for smoother surface finish. Table 2 shows that in the metal feedstock the powder volume is $63 \%$ of the material and rest of the $37 \%$ volume is taken by the plastic binder. For the ceramic feedstock, volume of ceramic powder is $47 \%$ and $53 \%$ volume is taken by plastic binder. For the metal feedstock, weight of the plastic binder is $10 \%$ of the total weight of the material whereas for the ceramic feedstock, the weight of the plastic binder is about $20 \%$ of the total weight of the material. So, both from volume and weight considerations, the metal feedstock has less amount of plastic binder compared to the ceramic feedstock. A comparative picture of the viscosity and pvT diagrams of the standard grade of Catamold metal and ceramic feedstock are presented in Fig 2. For both the feedstocks, the viscosity level is higher than that for a conventional thermoplastic material. The higher viscosity of Catamold feedstock is contributed by the powder content in the materials. The drop in viscosity at higher shear rates is significant for both materials hence the flow-related increase in pressure for filling narrow cross sections will be relatively small for both materials. The ranges of shear rates for viscosity measurement of metal and ceramic feedstocks are different as it can be seen in Plot A of Fig 2. This is because the plot is edited form the information presented in reference [14] and [15] and there, the shear rate ranges were different for the two materials. Nevertheless, the higher viscosity of ceramic feedstock compared to the metal feedstock is clearly visible in Plot A though the ceramic material contains larger fraction of plastic binder. The higher viscosity of ceramic feedstock is contributed by the smaller particle size of the material. The surface to volume ratio for ceramic 
powder is lager compared to the metal powder. Due to the relatively larger surfaces of the ceramic particles, a larger interfacial interactions between powder particles and plastic binder is created which contributes to the higher viscosity of the material. The pvT-diagrams (Fig. 2- plot B and C) show the change in specific volume as a function of temperature and pressure for the two materials. The ceramic feedstock shows higher specific volume compared to the metal feedstock. The main contributor to the increase in specific volume is coming from the plastic binder. The semi-crystalline polyacetal binder is clearly reflected in the pvT curves of the Catamold feedstocks. Both data sets show typical curves of a semi-crystalline material, in this case with a very distinct increase in specific volume and a change of the average slope at around $160{ }^{\circ} \mathrm{C}$. The higher powder load of Catamold $316 \mathrm{~L}$ is also indicated in the pvT curves, as the specific volume shows smaller absolute values for the metal feedstock.

The test geometry used for the experiment was a flat disc with diameter of $8 \mathrm{~mm}$ and thickness of $1 \mathrm{~mm}$. The machine used for moulding of the test samples was an Engel ES 80/25 HL-Victory machine with a screw diameter of $18 \mathrm{~mm}$ and clamping force of 25 tons. The test geometry, moulding machine and moulded test parts are shown in Fig. 3. The observation during the moulding trial showed that both the Catamold feedstocks were difficult to mould as they had a narrow process window. For the comparative purpose, the same part geometry was used for moulding of the both materials. Even though both feedstocks used the same binding materials, de-moulding was more difficult for the ceramic feedstock compare to metal feedstock. The increased difficulty associated with the demoulding of the ceramic parts aroused from the lower green 
ASME - Journal for Micro and Nano-Manufacturing

strength and higher compaction of the material in the mould cavity. This can be explained with the particle sizes, mechanical strength of green parts and shrinkage of the parts after moulding. The ceramic powder with significantly smaller particle size allowed higher compaction of the feedstock in the mould cavity. The green ceramic parts (parts after moulding, before debinding and sintering) were more fragile compared to the metal green parts even though the ceramic material had higher content of plastic binder. The reason for this can again be explained with the smaller particle size and the larger surface to volume ratio of the ceramic particles. Due to the high surface to volume ratio of the ceramic particles (as the particle size is smaller compared to the metallic particles), even after the presence of higher amount of plastic binder a relatively weak link was established between two neighboring creaming particles by the plastic binder during the injection moulding process, and this was the reason for weaker green strength of the ceramic feedstock. To make a strong green part, a good bonding between the powder particles is required and this bonding is made by plastic binder. When the powder particle size is smaller (which is the case with ceramic powder) the surface area of the particles becomes relatively larger compare to the volume of the part. The large surface of the particles does not get adequate wetting or covering with the plastic binder. That means that the bonding between two neighboring ceramic particles happens without the presence of adequate plastic binder and that makes the ceramic green parts weaker. On the other hand the particle size is bigger for the metal powder and that minimizes the surface to volume ratio and gives better wetting of the metal particles with the plastic binder hence better bodings with 
the neighboring particles, and this is the reason for stronger green metal parts

compared to ceramic parts. Moreover the shrinkage of the green parts was less for ceramic parts compared to the metal parts (shrinkage will be discussed in details later). All these facts made the demoulding of the moulded ceramic parts more difficult compared to the moulded metal parts. Both materials showed difficulties to perform a DOE (Design of Experiment) due the narrow process windows. For this reason the moulding of the parts was done only with the standard process condition recommended by the material supplier for the both materials. Important moulding parameters used for moulding CIM and MIM parts are presented in the Table 3.

After moulding, debinding and sintering processes were carried out to produce the final metal and ceramic parts (test samples). Sintering and debinding were carried out according to the recommendation given by the material manufacturer. The debinding and sintering of the metal parts were carried out at Sintex A/S, Hobro, Denmark and in Formatec Ceramics BV, Goirle, The Netherlands for the ceramic parts. After moulding, debinding and sintering, the test parts were used in various metrological investigations. For the testing of the effects of environmental conditions on the moulded parts, parts were treated with specific environmental conditions which will be discussed later. The roughness measurements of the part surfaces were done with Alicona Infinite Focus Microscope. For dimensional and geometrical measurements, an optical coordinate measuring machine (Optical CMM Demeet 220) was used. For morphological and microscopic investigations an optical microscope (Olympus GX 41) was used. 


\section{RESULTS AND DISCUSSION}

\subsection{Shrinkage of the moulded parts}

One of the most important considerations for the powder moulded components is the part shrinkage. For the comparative analysis of shrinkage of moulded metallic and ceramic components, the diameter and thickness of the green and sintered parts were measured with the optical CMM and compared with the mould dimensions. In Fig. 4-A, the results of average diameter measurements for green and sintered parts are presented in comparison with the measurements taken on the mould cavity. The average was taken from 8 different sample measurements. The average shrinkage of the green CIM parts after moulding was about $0.97 \%$, which was lower than the $3.8 \%$ shrinkage of green metal parts. The larger post moulding shrinkage for metal was contributed by the larger thermal expansion of the materials. Metal has a thermal expansion coefficient which is about two times larger than the thermal expansion of the ceramic. For the sintered parts, the shrinkage was about $22 \%$ for ceramic parts and about $16.2 \%$ for metallic parts (presented in Fig. 4-B). The finer particles of the ceramic materials make a better compaction of the sintered part resulting in larger shrinkage of the final CIM parts. The relatively larger amount of plastic binder in ceramic feedstock is another reason for larger shrinkage of ceramic parts.

The comparison of diameter and thickness shrinkage for MIM and CIM parts is presented in Fig. 4-C. For both materials, the diameter had higher shrinkage compared to the part thickness resulting into a non-uniform shrinkage in different directions. The 
variation in the diameter and thickness shrinkage was influenced by the position of the moulding gate and directional flow of the moulding materials (during the production of the test parts, the moulding materials flowed perpendicular to the part thickness). What is important to notice is that there was no significant difference in shrinkage uniformity for MIM and CIM; in this consideration the process capabilities of the MIM and CIM were $\mathrm{m}$.

The weight of the moulded green parts and sintered parts were measured with the use of a Shimadzu AW220 scale with a resolution of $0.1 \mathrm{mg} .8$ parts were randomly selected both from CIM and MIM samples which were used for weight measurement before and after sintering. The results of the weight measurements are presented in Fig. 5. The average weight of the metal green parts was $341 \mathrm{mg}$ with a standard deviation of $14 \mathrm{mg}$. For the CIM parts the average weight of the green parts was $204 \mathrm{mg}$ a with standard deviation of $1.5 \mathrm{mg}$. The average weight of the sintered CIM parts was $165 \mathrm{mg}$ with a standard deviation of $0.9 \mathrm{mg}$. The weight reductions of the sintered parts in comparison with the green parts were $11 \%$ and $19 \%$ for MIM and CIM parts respectively and these reductions were close to the weight percentage of the plastic binders in the MIM and CIM feedstocks.

\subsection{Surface replication and surface roughness}

For comparative roughness investigation, the roughness of one of the flat surfaces of disc parts were measured for both green and sintered part in case of both the materials. Measurements were done in the middle of the parts in a $1.25 \times 0.225$ 
$\mathrm{mm}^{2}$ area (as shown in Fig. 6). Roughness measurements were performed according to ISO 25178-2 [16] standard. For the analysis of the surface roughness three 3D roughness parameters (Sa, Sq and Sz) were chosen. Sa and Sq are the average and root mean square roughness respectively evaluated over the complete 3D surface. Sz is the difference between the maximum value of the peak height and the valley depth on the surface within the measured area. Fig. 7 presents the comparative results of roughness measurements (Sa-plot A, Sq-plot B and Sz-plot C) done on the green parts, sintered parts and on the mould surface. The mould had an average roughness of Sa=2.5 $\mu \mathrm{m}$ and $\mathrm{Sq}=3.25 \mu \mathrm{m}$. Moulded green parts were rougher compared to the mould for both the materials.

When the roughness of the green and sintered parts is compared, it is evident that sintering smoothens the surface. There is a significant decrease on the roughness values for the sintered parts in comparison with the green parts for all roughness parameters. When the roughness parameters of the two materials - metal and ceramic are compared, there is no significant difference in the achievable average roughness (Sa), not even in Sq value. It is clear that in all roughness parameters there are larger standard deviations associated with metal parts. These standard deviations are obtained from the average roughness measurement of 8 different samples. From these standard deviations it can be concluded that the more identical part production in term of surface roughness was possible with CIM process compared to MIM process. Shrinkage of different roughness parameters is higher in the final metal parts compared with the green parts values. When the roughness shrinkage of the sintered parts is considered 
based on the mould roughness, there is a significant difference in roughness parameters for $\mathrm{CIM}$ and MIM parts (presented in plot 7-E). For MIM, the shrinkage in $\mathrm{Sz}$ is much less compared to CIM parts which reveals that the replications of mould surface peaks and valleys were better with the metal parts and a more accurate reproduction of mould surface was possible with Catamold 316L-A material. The better replication is given by Catamold 316L-A due to its lower viscosity compared to the Catamold TZP-A.

An important manufacturing consideration is the tolerance with which the parts can be produced, i.e. how reproducible the process is, depending on process settings, material variations etc. In the current investigation the tolerance capabilities of MIM and CIM processes with the use of Catamold 316L-A and Catamold TZP-A respectively were determined. The process tolerance included both the reproducibility (dispersion of measurements carried out on different parts produced in the same processing conditions) and the measuring uncertainty (calculated according to ISO 15530-3 [17], i.e. including both measurement repeatability and calibration). The achievable tolerances for disc diameter, thickness and flatness for the metal and ceramic parts are listed in Table 4. The table shows that slightly better dimensional tolerance (especially for the diameter and thickness) was possible with the CIM process compared to the MIM process.

\subsection{Environmental test}

Injection moulded parts have a tendency to absorb moisture after injection moulding. To identify the effects of moisture absorption by the green ceramic and metal 
parts, an environmental wettability test was carried out. Five metallic and ceramic green parts were randomly selected for the test. The part diameter and flatness were measured with the optical CMM for the selected samples. Then the parts were submerged under water for 24 hours to let the parts absorb moisture and finally the parts were wiped with dry cloth to remove the extra water from the surface. After the treatment, the part diameter and flatness were measured again to find the influence of the moisture absorption on the part dimensions. Fig. 8 illustrates the results of the wettability test showing a higher influence on the dimensions as well as on the flatness error of the metallic green parts.

An increase of $0.25 \%$ was observed on the diameter of the metallic parts in comparison to the $0.03 \%$ increase on the ceramic parts due to the influence of the moisture. In addition, the flatness error of the metallic parts was 5.4\% decreased compared to a $2.9 \%$ decrease of the flatness error of the ceramic parts. The different particle sizes and porosities inside the green parts were the reasons for the different behavior under the influence of environmental conditions. The green metal parts were more affected by moisture due to larger particle size of the powder and the presence of higher amount of porosities in the moulded green parts (porosity of the MIM and CIM parts will be discussed more in details in the next section).

\subsection{Morphological investigation}

The mechanical properties of moulded ceramic and metallic parts are affected by the amount of porosity inside the final parts. The source of porosity for a given material 
with specific powder- binder ratio is mainly the sintering process. The relative amount of porosity will be changed if powder-binder ratio is changed. Sintering for ceramic and metal parts is done at temperatures below the melting point of the metal or ceramic powder, the sintering temperature is usually high enough to start the recrystallization process but low enough so that the particles remain unmelted [1]. In the experimental case the sinterings were performed at $1350^{\circ} \mathrm{C}$ and $1500^{\circ} \mathrm{C}$ for metal and ceramic respectively. Whereas the melting point of Stainless steel $316 \mathrm{~L}$ is $1400^{\circ} \mathrm{C}$ and for Catamold TZP-A, it's about $2700^{\circ} \mathrm{C}$ After sintering, both the ceramic and metallic sintered parts are left with residual porosity, which affects the mechanical properties of the final parts. For the comparative analysis of the porosity distribution inside the metallic and ceramic parts, the moulded and sintered parts from the both classes of materials were sectioned along the middle of the parts. Then the surface was polished for optical investigation. The samples were investigated in three different locations of the cross-sections based on the distance from the moulding gate (close to the gate, in the middle and far from the gate). Some pictures from the porosity investigation are presented in Fig. 9. Within the same parts, there was no significant difference in the porosity distribution in three different sections. However, in all sections of the metal parts, the relative amount of porosity was higher compared to ceramic parts. Porosity analysis of the optical images with the help of SPIP 6.1.1 image processing software, showed that there was approximately $4 \%$ higher porosity in the sectioned surface of the sintered metal parts compared to ceramic parts. The larger particle size of the metal powder is the prime reason for higher porosities in the metal parts. 


\section{CONCLUSION}

This paper presents a comparative study of two branches of PIM processes. Both processes- CIM and MIM are in a stage now where they can offer exciting possibilities for mass production of extremely precise and complex net shape products. For some applications, PIM process presents a dilemma for choosing between MIM and CIM as both the material classes can offer specific advantages and the process steps are identical. So a comparative study about the process capabilities between CIM and MIM was conducted for the thorough understanding of the processes and to select the right material and process for the right application. The uniformity and repeatability of the shrinkage and surface replication were studied for CIM and MIM. More identical part production was possible with CIM process compared to MIM process when surface roughness was considered; on the other hand more accurate replication of the mould surface was possible with MIM process. Geometrical tolerances of the parts moulded with Catamold TZP-A were slightly better than Catamold 316L-A, as shown from the experimental investigation. Catamold 316L-A green parts were more affected by environmental condition like humidity and moisture. Metal sintered parts showed relatively higher amount of porosity compared to the ceramic parts which had low and uniformly distributed porosities in the sintered parts.

The future work should focus on the comparison of the uniformity of the shrinkage and surface roughness in different sections of the parts made by MIM and CIM feedstock. As reported in [18], the shrinkage in metal parts is not uniform in different section of the parts and in different features of the parts. The shrinkage 
difference is observed in different locations based on the distance from the moulding gate in case of MIM feedstock. For CIM feedstock the same studies should be repeated and compared with results obtained form the MIM. The mould insert used for the current investigation had relatively high surface roughness (Sa=2.5 $\mu \mathrm{m})$. Future investigation should focus on making an optically smooth surface on the mould insert to find the achievable limit of surface roughness for MIM and CIM parts both at green and sintered state. More in-depth analysis of surface roughness obtained from fine mould inserts with the application of different powder materials (with different ranges of particle sizes) and the normalization of the part roughness with respect to the mould surface etc. will be the issues of future investigation

\section{ACKNOWLEDGMENT}

This paper reports work undertaken in the context of the project "Hi-MICRO" (High Precision Micro Production Technologies, http://www.hi-micro.eu/). Hi-MICRO is a Collaborative Project supported by the European Commission in the 7th Framework Programme (Grant agreement no: 314055). Sintex A/S, Hobro, Denmark and Formatec B.V, Goirle, The Netherlands, are acknowledged for their help in the sintering of metal and ceramic parts respectively. 


\section{REFERENCES}

[1] Gutiérrez, J. G. et al., 2012, "Powder Injection Molding of Metal and Ceramic Parts", ISBN: 978-953-51-0297-7, InTech publication, page 65-88.

[2] Volker, P., 2011, "A review of the current status of MicroPIM", Powder Injection Molding International, vol 5(3) page 27-42.

[3] Attia, U., Alcock, J., 2011, "A review of micro-powder injection moulding as a microfabrication technique", J Micromechanics ; vol 21(4), page 1-41.

[4] Drummer, D., Messingschlager, S., 2014, "Ceramic injection molding material analysis, modeling and injection molding simulation", Proceedings of PPS-29, AIP Conf. Proc. 1593, pages 582-586; doi: 10.1063/1.4873848 2014.

[5] Shye, Y., H., Muhamad, N., Sulong, A., B., 2011, “Micro Powder Injection Molding ( $\mu \mathrm{PIM})$ : Review", Applied Mechanics and Materials, vol 52-54, pages 91-96.

[6] Petzoldt, F., 2008, "Micro powder injection moulding-challenges and opportunities", Powder Injection Moulding International, Vol. 2 (1), pages 37-42.

[7] Richerson, D., W., 2005, “Modern Ceramic Engineering: Properties, Processing, and Use in Design", CRC Press Taylor \& Francis Group, 3rd edition, ISBN 9781574446937.

[8] Inovar Communications Ltd International, 2012-2013, Powder Metallurgy Directory IPMD, 15th Edition, ISBN: 978-0-9558223-2-2, Publisher: Inovar Communications Ltd.

[9] Hanemann, T., Honnef, K., Müller, T., Weber, O., 2011, “New methacrylate-based feedstock systems for micro powder injection moulding" Microsystem Technologies, vol 17(3), pages 451-457.

[10] Moritz, T., Lenk, R., 2009, "Ceramic injection moulding: production, materials and applications", Powder Injection Moulding International, Vol.3 (3), pages 23-33.

[11] Imgrund, P., Rota, A., Kramer, L., 2005, "Processing and properties of bi-material parts by micro metal injection moulding", Proceedings of the First International Conference on Multi-Material Micro Manufacture, Imprint: Elsevier Science, eBook ISBN: 9780080462554, pages 131-134.

[12] Ruh, A., Piotter, V., Plewa, K., Kleissl, H., J., R., 2011, “Development of TwoComponent Micropowder Injection Molding (2C-MicroPIM)-Process Development", 
International Journal of Applied Ceramic Technology, Int. J. Appl. Ceram. Technol., vol 8 (3), pages 610-616, DOI:10.1111/j.1744-7402.2009.02468.x.

[13] Islam, A., Nørgaard, H., N., Tang, P., T., Jørgensen, M.B., Ørts, S.F., 2010 "Twocomponent microinjection moulding for MID fabrication", in journal: Plastics, Rubber \& Composites (ISSN: 1465-8011) (DOI: 10.1179/174328910X12691245470356), vol: $39,(7)$, pages $300-307$.

[14] BASF AG, 2003, Catamold Feedstock for Metal Injection Molding : Processing Properties - Applications.

[15] BASF SE, 2009, Catamold Feedstock for Powder Injection Molding - Guidelines for processing CIM feedstock.

[16] ISO 25178-2:2012: "Geometrical product specifications (GPS) - Surface texture: Areal - Part 2: Terms, definitions and surface texture parameters" published on: 2012-04-01, edition: 1 (Monolingual), ICS: 17.040.20, stage: 60.60 (2012-03-28), TC/SC: ISO/TC 213.

[17] ISO 15530-3:2011, “Geometrical product specifications (GPS) - Coordinate measuring machines (CMM): Technique for determining the uncertainty of measurement - Part 3: Use of calibrated workpieces or measurement standards", published on: 2011-10-15, edition: 1 (Monolingual), ICS: 17.040 .30 , stage: 60.60 (2011-10-06), TC/SC: ISO/TC 213.

[18] Islam, A., Giannekas, N., Marhöfer, D., M., Tosello, G., Hansen, H., N., 2015, "The shrinkage behavior and surface topographical investigation for micro metal injection molding", AIP Conf. Proc. 1664, 110007 (2015); doi: 10.1063/1.4918482. 


\section{Figure Captions List}

Fig. 1 Catamold 316L-A raw material for metal moulding (left) and Catamold TZA-P raw material for ceramic moulding (right).

Fig. 2 A-Comparative flow properties of standard grade of Catamold 316L and Catamold TZP (edited from reference [14] and [15]). B- pvT diagram for Catamold TZP (edited from [15]). C- pvT diagram for standard grade Catamold 316L (edited from [14]).

Fig. 3 Geometry of the test part (left), moulding machine used for the experiment (middle), moulded test parts (left).

Fig. $4 \quad$ Comparative shrinkage of MIM and CIM parts in diameter and thickness.

Fig. 5 Comparative weight reduction of MIM and CIM parts before and after sintering.

Fig. 6 Roughness measurement taken in the middle of mould insert, ceramic parts and metal parts (scan area $1.25 \mathrm{~mm} \times 0.225 \mathrm{~mm}$ ).

Fig. 7 Comparative results of roughness measurements on mould, metal and ceramic part surfaces.

Fig. 8 The influence of the moisture on the mean diameter of metallic and ceramic green parts (plot A) and the influence of the moisture on the mean flatness of metallic and ceramic green parts (plot B).

Fig. 9 Pictures from the porosity analysis of MIM and CIM parts with Optical instruments and SPIP 6.1.1 image processing software. Pictures shows 
ASME - Journal for Micro and Nano-Manufacturing

relatively higher amount of porosities in all sections of metal parts (pictures were taken in three different locations of sintered parts based on the distance from the moulding gates). 


\section{Table Caption List}

Table 1 Summary of the comparison between powder injection moulding (MIM and $\mathrm{CIM}$ ) and plastic injection moulding.

Table 2 Specification of the raw materials used for the experimental trial.

Table $3 \quad$ Moulding process parameters used to mould the test parts with Catamold 316-LA and Catamold TZP-A.

Table $4 \quad$ Comparative process capability of CIM and MIM process in terms of part tolerances. 
Figures and Tables
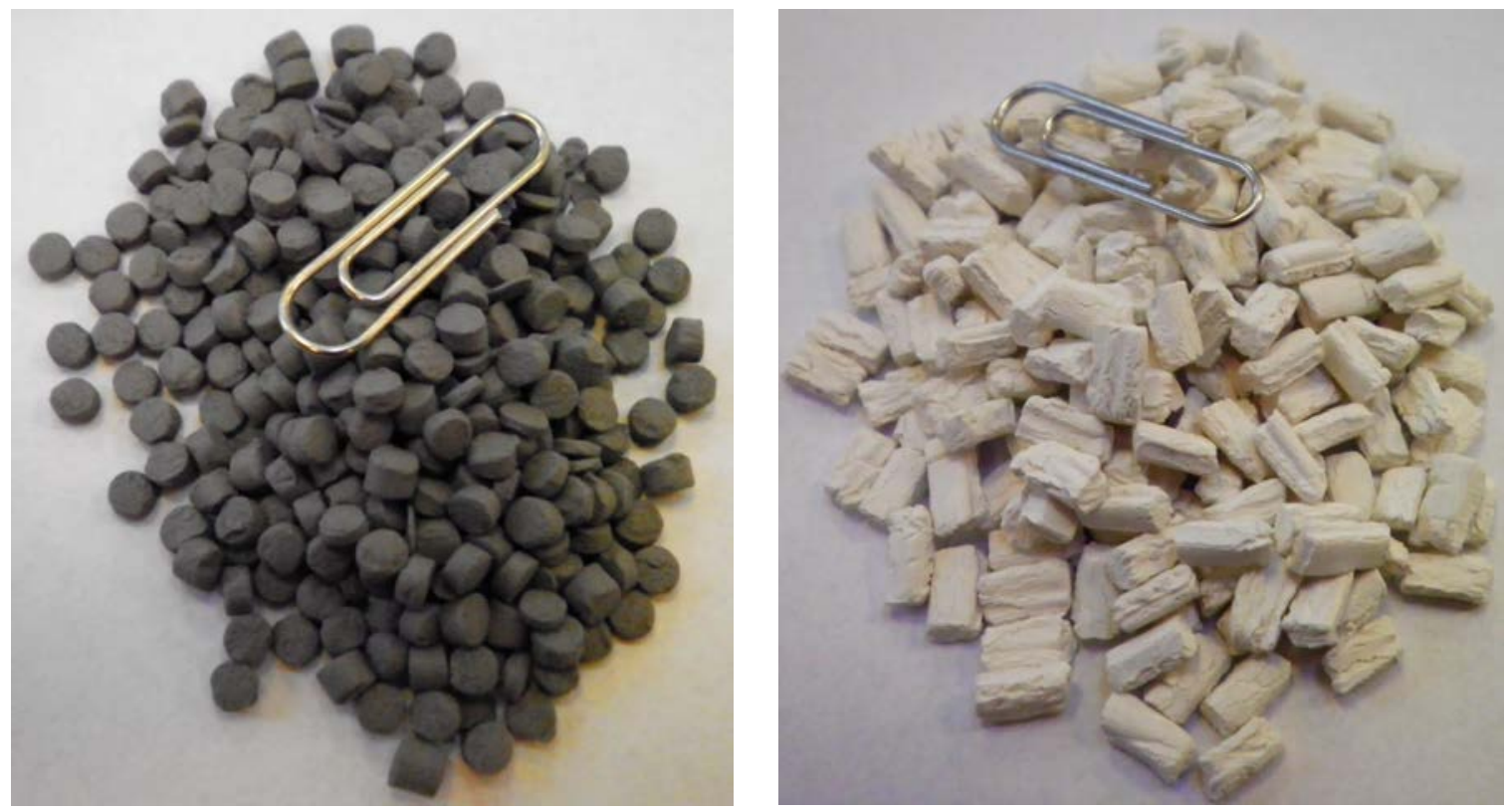

Fig. 1. Catamold 316L-A raw material for metal moulding (left) and Catamold TZA-P raw material for ceramic moulding (right). 

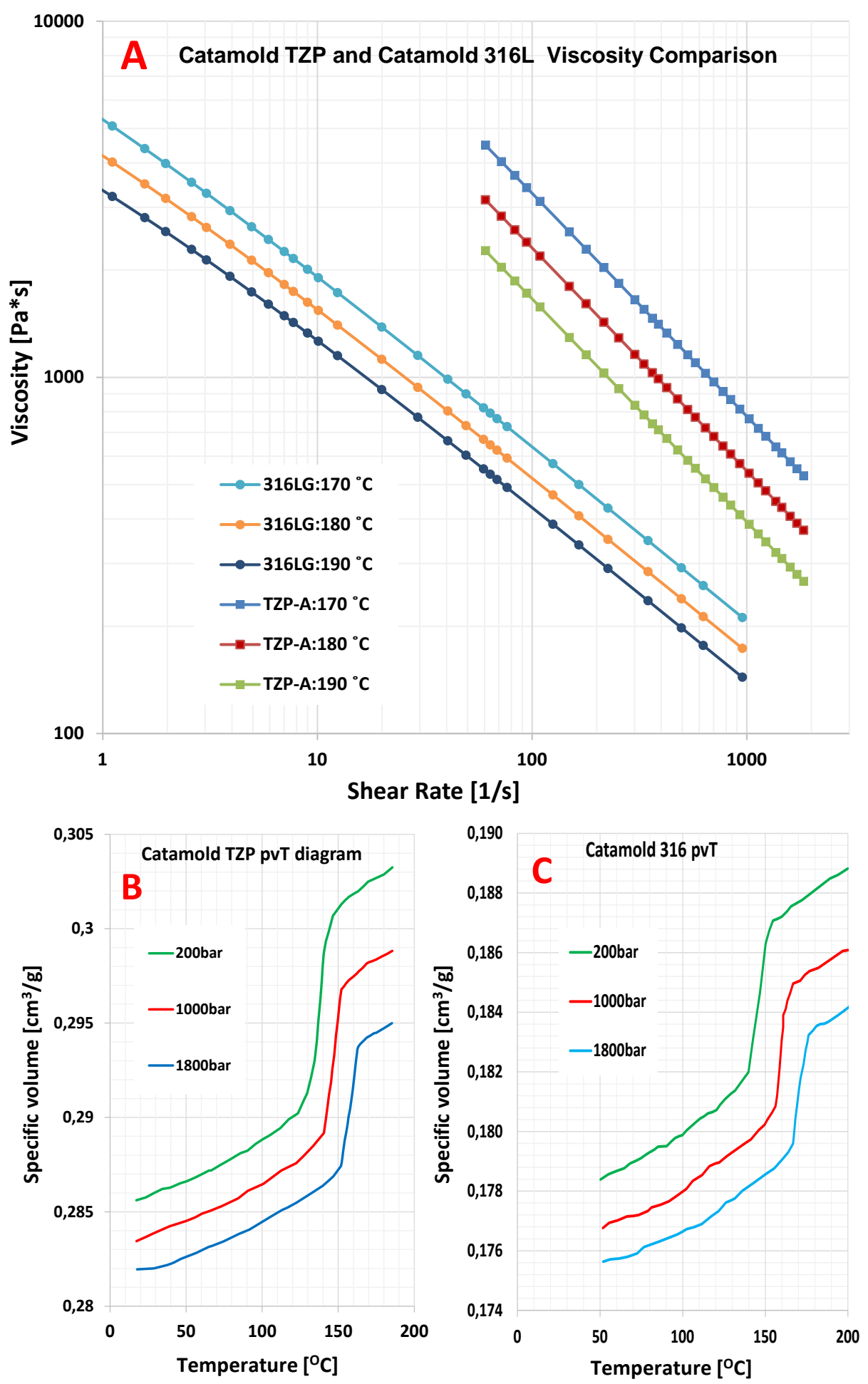

Fig. 2. A- Comparative flow properties of standard grade of Catamold 316L and Catamold TZP (edited from reference [14] and [15]). B- pvT diagram for Catamold TZP (edited from [15]). C- pvT diagram for standard grade Catamold 316L (edited from [14]). 


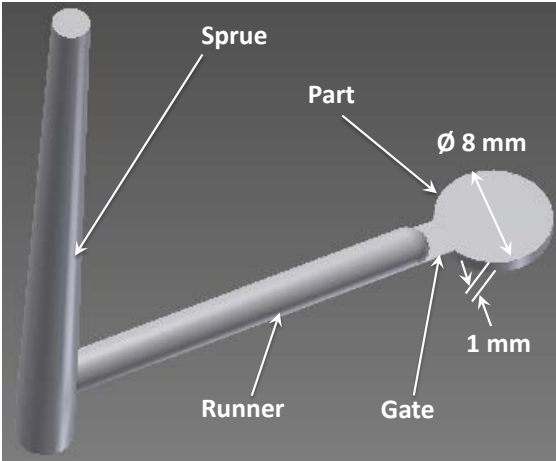

Disc part with the sprue, runner and gate

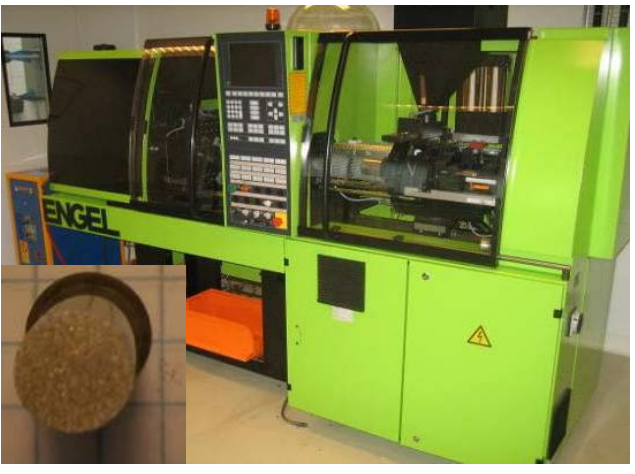

Moulding machine and mould insert

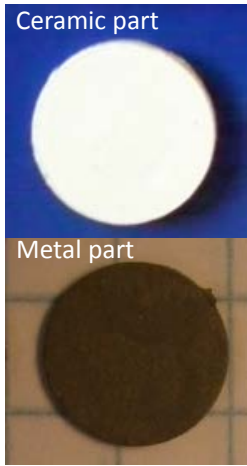

Moulded parts

Fig. 3. Geometry of the test part (left), moulding machine used for the experiment (middle), moulded test parts (left). 
Mean Disk Diameter Comparison

A $\square$ Green parts $\square$ Sintered parts $\square$ Moulds

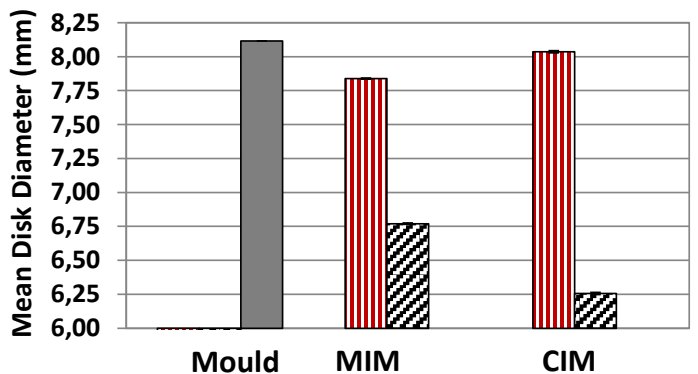

Shrinkage of sintered MIM \& CIM parts compared with Green parts

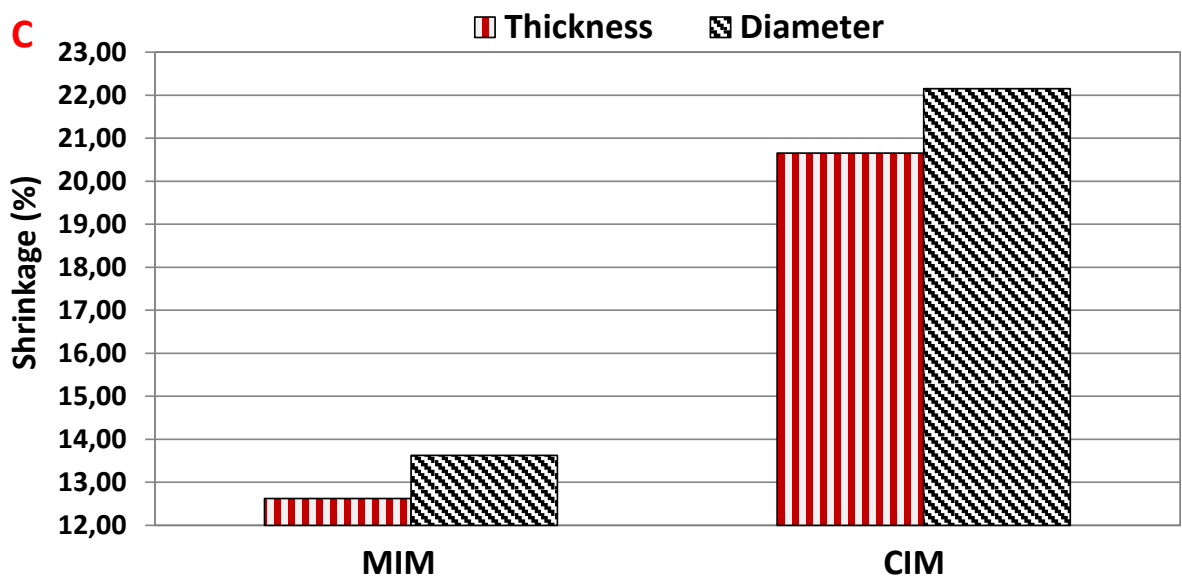

Diameter Shrinkage from Mould dimension

B $\square$ Green parts $\square$ Sintered parts

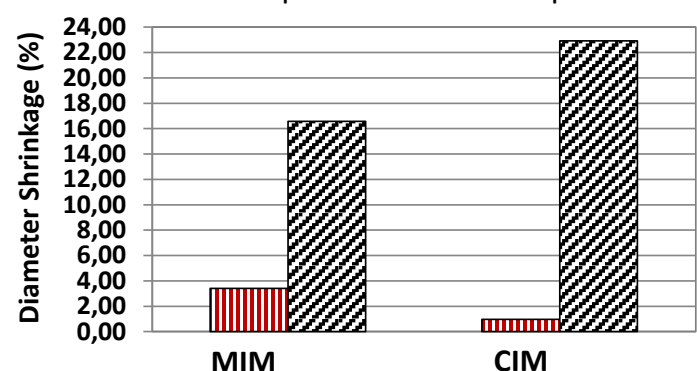

Fig. 4. Comparative shrinkage of MIM and CIM parts in diameter and thickness. 
ASME - Journal for Micro and Nano-Manufacturing

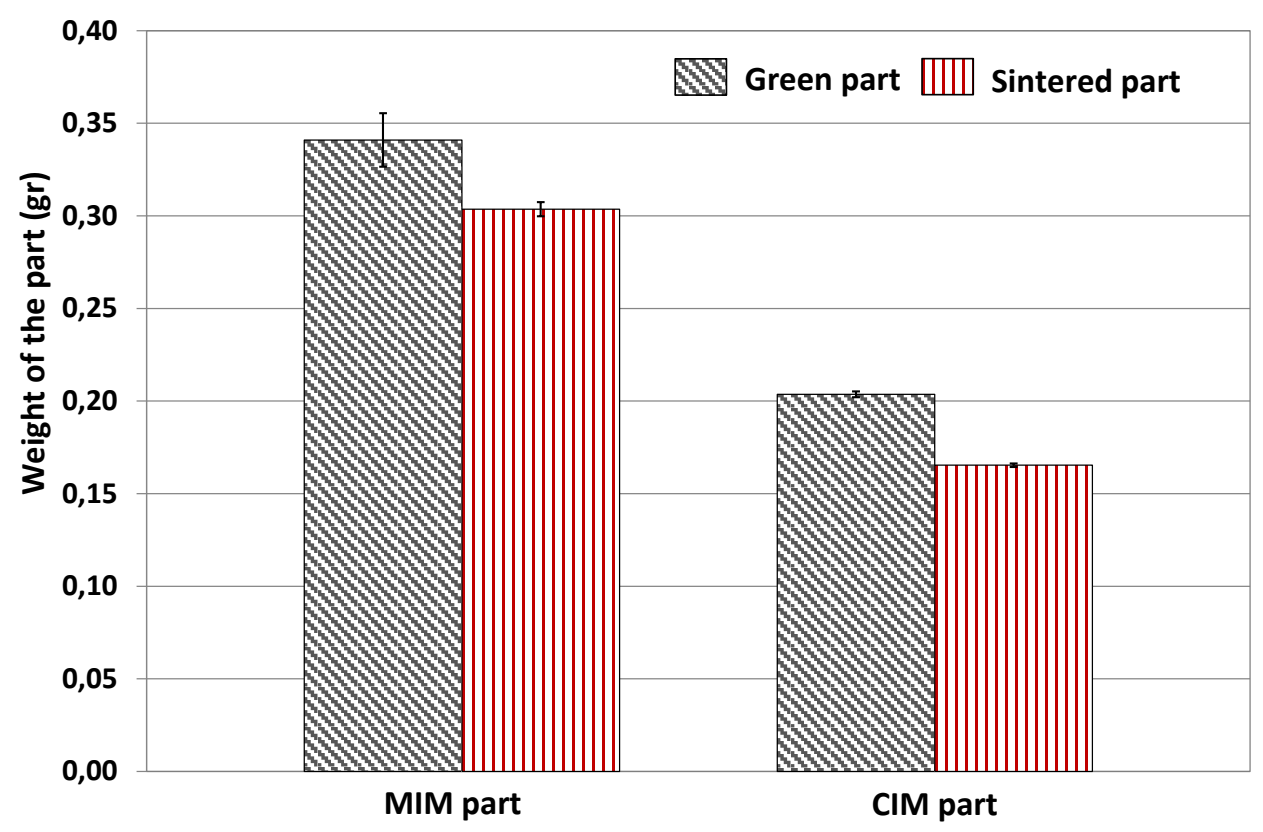

Fig. 5. Comparative weight reduction of MIM and CIM parts before and after sintering. 

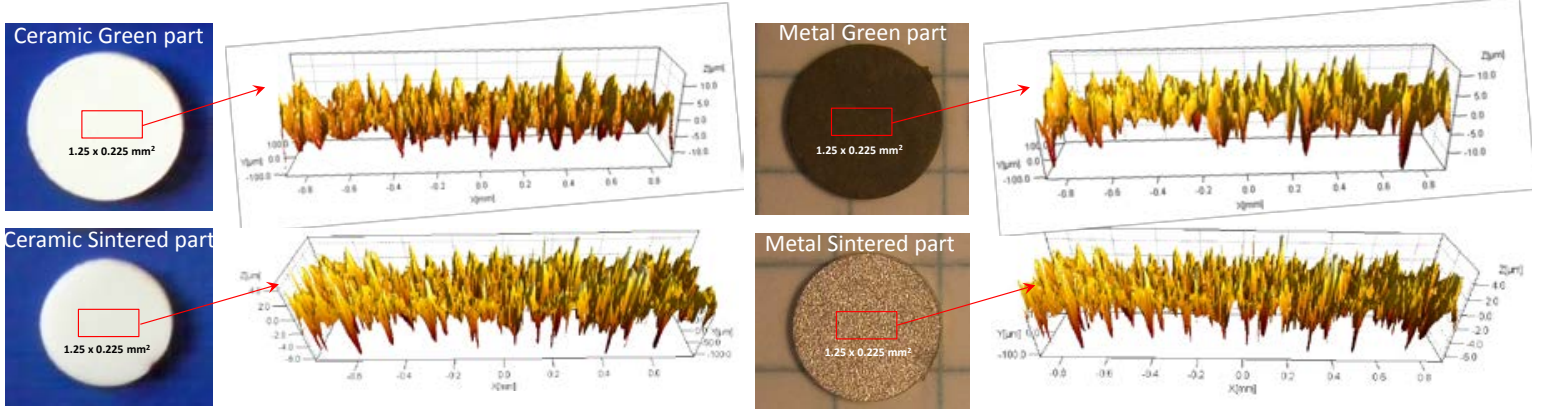

Fig. 6. Roughness measurement taken in the middle of mould insert, ceramic parts and metal parts (scan area $1.25 \mathrm{~mm}$ x $0.225 \mathrm{~mm}$ ). 
A Mean Sa roughness comparison
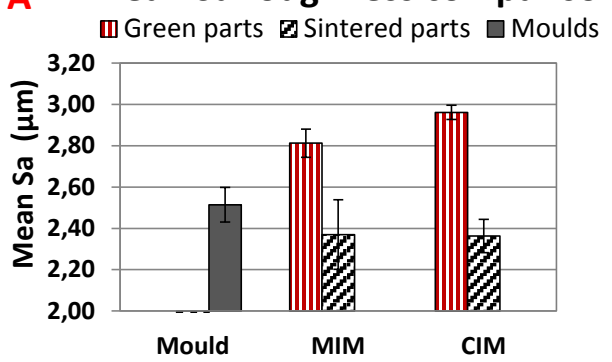

Mean Sz roughness comparison

C $\square$ Moulds $\square$ Green parts $\square$ Sintered parts

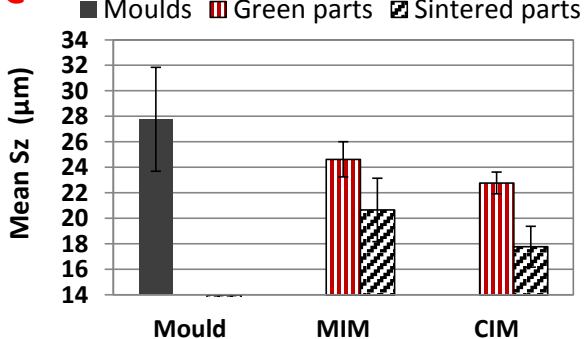

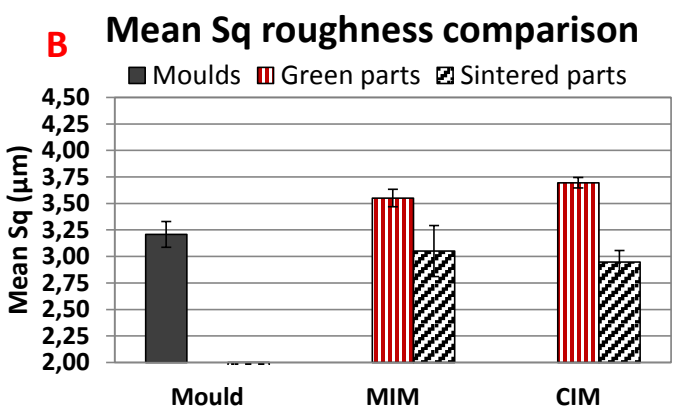

Roughness reduction in \% from Green values

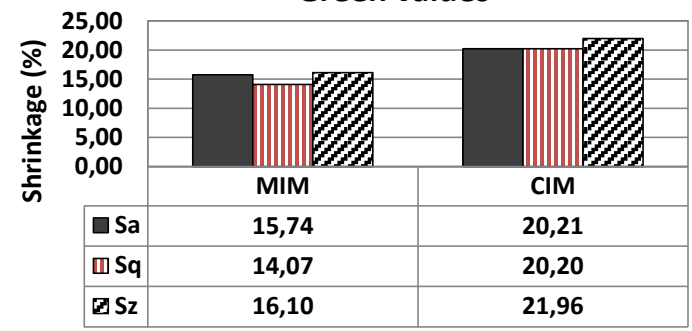

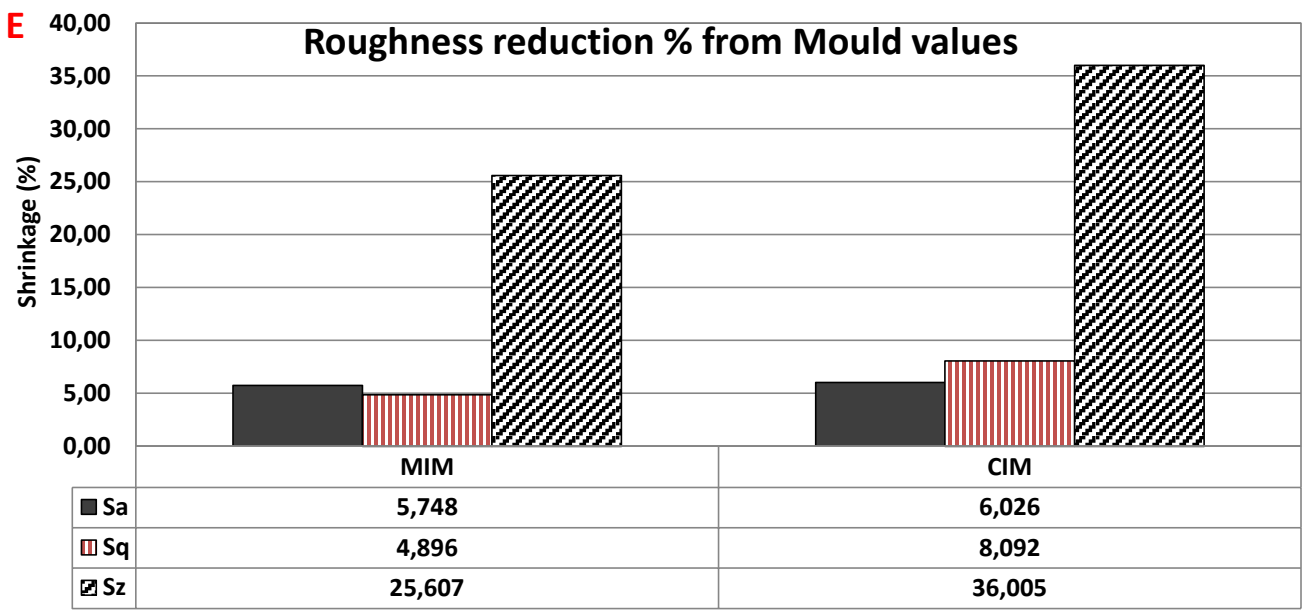

Fig. 7. Comparative results of roughness measurements on mould, metal and ceramic part surfaces. 

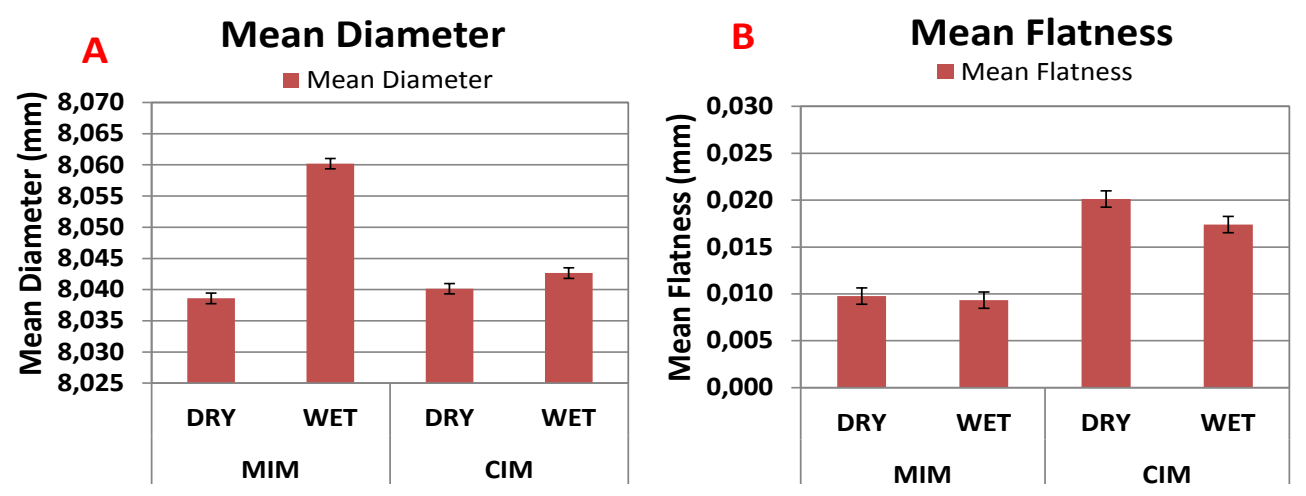

Fig. 8. The influence of the moisture on the mean diameter of metallic and ceramic green parts (plot A) and the influence of the moisture on the mean flatness of metallic and ceramic green parts (plot B). 


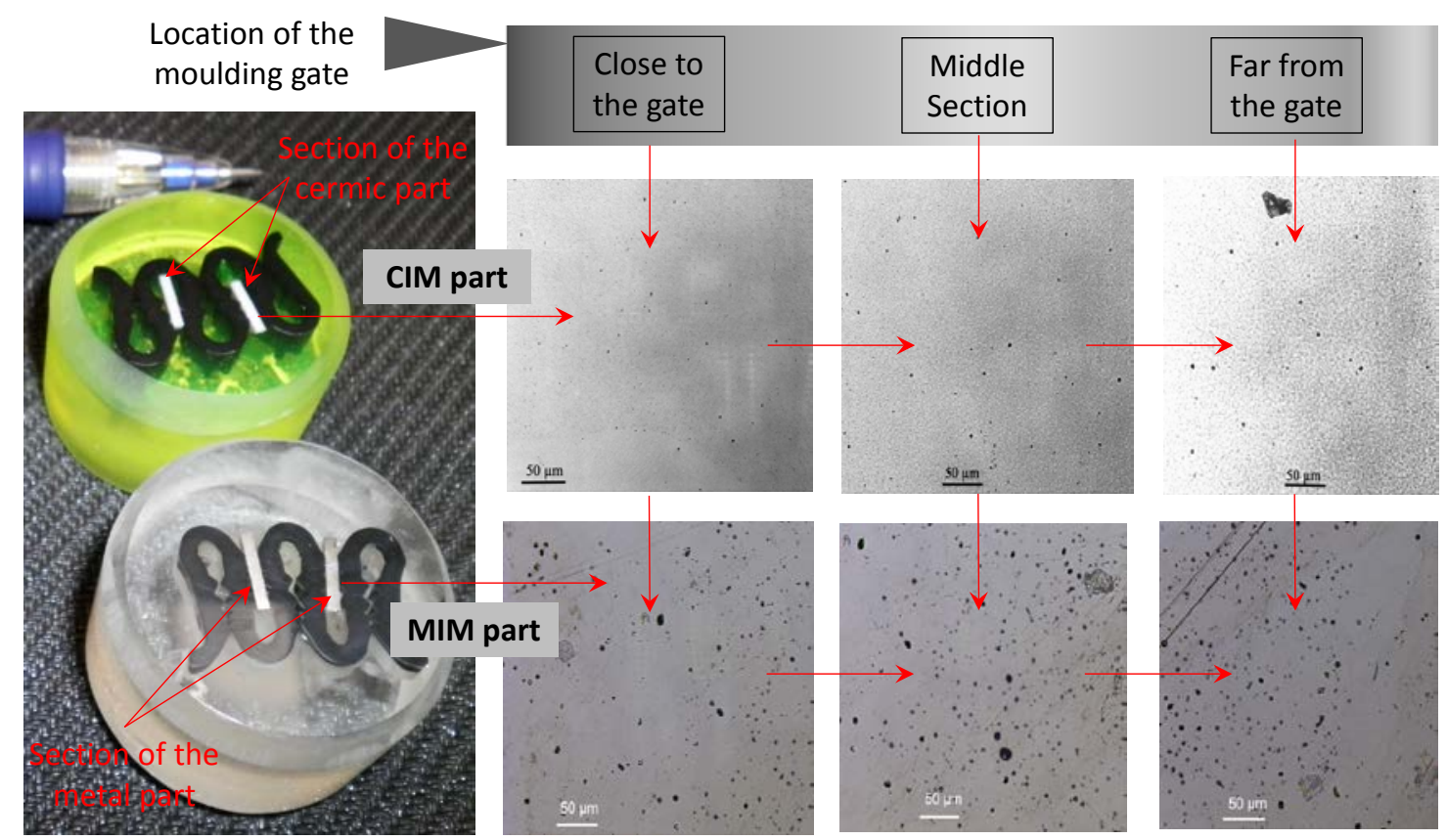

Visualization of porosities in differens sections of CIM and MIM parts with optical microscope
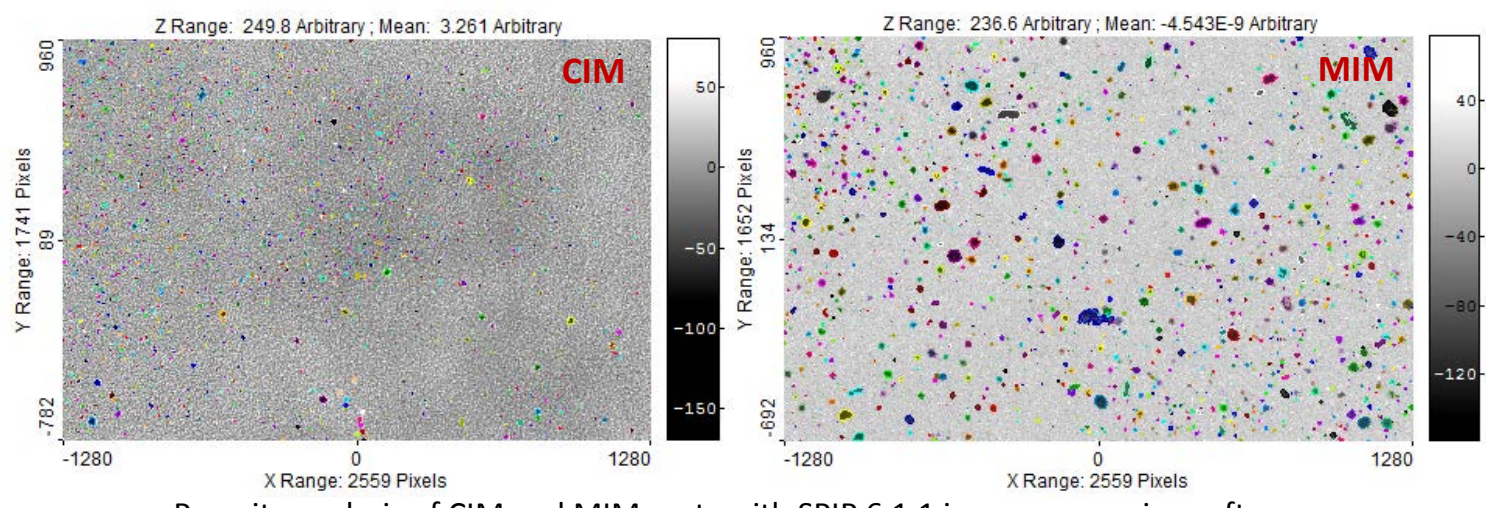

Porosity analysis of CIM and MIM parts with SPIP 6.1.1 image processing software

Fig. 9. Pictures from the porosity analysis of MIM and CIM parts with Optical instruments and SPIP 6.1.1 image processing software. Pictures shows relatively higher amount of porosities in all sections of metal parts (pictures were taken in three different locations of sintered parts based on the distance from the moulding gates). 
Table 1. Summary of the comparison between powder injection moulding (MIM and CIM) and plastic injection moulding.

\begin{tabular}{|l|l|l|l|}
\hline Molding process & plastics $(\mu \mathrm{IM})$ & metals $(\mu \mathrm{MIM})$ & ceramics $(\mu \mathrm{CIM})$ \\
\hline Feature size & $>10 \mu \mathrm{m}$ & $>50 \mu \mathrm{m}$ & $>10 \mu \mathrm{m}$ \\
\hline Aspect ratio & $>20$ & $>10$ & $<15$ \\
\hline Precision & $>1 \mu \mathrm{m}^{\mathrm{a}}$ & $<10 \mu \mathrm{m}$ & $<3 \mu \mathrm{m}$ \\
\hline$>0.1 \mu \mathrm{m}^{\mathrm{b}}$ & $<0.01 \mu \mathrm{m}$ & $<1 \mu \mathrm{m}$ & $<0.2 \mu \mathrm{m}$ \\
\hline Roughness (Ra) & $\begin{array}{l}\text { shrinkage, melt } \\
\text { viscosity, packing }\end{array}$ & $\begin{array}{l}\text { sintering, particle size, } \\
\text { feedstock viscosity, powder } \\
\text { loading }\end{array}$ & $\begin{array}{l}\text { sintering, particle size, } \\
\text { feedstock viscosity, powder } \\
\text { loading }\end{array}$ \\
\hline precisionce and & {$[2,5,28-30]$} & {$[8,14,25,29,31]$} & {$[8,14,25,29,31]$} \\
\hline
\end{tabular}

${ }^{a}$ with conventional injection molding machines

${ }^{b}$ with dedicated micro injection molding machines 
ASME - Journal for Micro and Nano-Manufacturing

Table 2. Specification of the raw materials used for the experimental trial.

\begin{tabular}{|l|l|l|l|l|l|l|}
\hline Material & Powder & Binder & Particle size & $\begin{array}{l}\text { Powder } \\
\text { content }\end{array}$ & $\begin{array}{l}\text { Debinding } \\
\text { atmosphe } \\
\text { re }\end{array}$ & $\begin{array}{l}\text { Sintering } \\
\text { atmosphere }\end{array}$ \\
\hline $\begin{array}{l}\text { Catamold } \\
\text { 316L-A }\end{array}$ & $\begin{array}{l}\text { Austenitic } \\
\text { stainless- } \\
\text { steel type } \\
\text { 316L }\end{array}$ & $\begin{array}{l}\text { Polyacetal } \\
\text { binder } \\
\text { system }\end{array}$ & $\begin{array}{l}\text { Approx. } \\
0.5-15 \mu \mathrm{m}\end{array}$ & $\begin{array}{l}63 \mathrm{vol} \% \\
\text { (approx.) } \\
90 \mathrm{wt} \% \\
\text { (approx.) }\end{array}$ & Nitric acid & $\begin{array}{l}100 \% \text { clean } \\
\text { and dry hydro- } \\
\text { gen }\end{array}$ \\
\hline $\begin{array}{l}\text { Catamold } \\
\text { TZP-A }\end{array}$ & $\begin{array}{l}\text { Polycrystal } \\
\text { line yttria- } \\
\text { stabilised } \\
\text { tetragonal } \\
\text { zirconia }\end{array}$ & $\begin{array}{l}\text { Polyacetal } \\
\text { binder } \\
\text { system }\end{array}$ & $\begin{array}{l}\text { Approx. } \\
0.2-0.5 \mu m\end{array}$ & $\begin{array}{l}47 \text { vol \% } \\
\text { (approx.) } \\
80 \text { wt \% } \\
\text { (approx.) }\end{array}$ & Nitric acid & Air \\
& & & & & & \\
\hline
\end{tabular}


ASME - Journal for Micro and Nano-Manufacturing

Table 3. Moulding process parameters used to mould the test parts with Catamold 316L-A and Catamold TZP-A.

\begin{tabular}{|l|l|l|}
\hline & Catamold 316L-A & Catamold TZP-A \\
\hline Melt temperature & $180^{\circ} \mathrm{C}$ & $180^{\circ} \mathrm{C}$ \\
\hline Mould temperature & $128^{\circ} \mathrm{C}$ & $128^{\circ} \mathrm{C}$ \\
\hline Injection speed (actual) & $80 \mathrm{~mm} / \mathrm{s}$ & $40 \mathrm{~mm} / \mathrm{s}$ \\
\hline Packing pressure & $900 \mathrm{bar}$ & $900 \mathrm{bar}$ \\
\hline Packing time & $5 \mathrm{sec}$ & $8 \mathrm{sec}$ \\
\hline Cooling time & $10 \mathrm{sec}$ & $15 \mathrm{sec}$ \\
\hline
\end{tabular}


ASME - Journal for Micro and Nano-Manufacturing

Table 4. Comparative process capability of $\mathrm{CIM}$ and MIM process in terms of part tolerances.

\begin{tabular}{|l|c|c|}
\hline \multicolumn{3}{|c|}{ Diameter } \\
\hline Mean Diameter & MIM & CIM \\
\hline Green Parts $(\mathrm{mm})$ & $8.073 \pm 0.006$ & $8.049 \pm 0.005$ \\
\hline Sintered Parts $(\mathrm{mm})$ & $6.927 \pm 0.008$ & $6.263 \pm 0.004$ \\
\hline \multicolumn{3}{|c|}{ Flatness } \\
\hline Mean Flatness & MIM & CIM \\
\hline Green Parts $(\mu \mathrm{m})$ & $13 \pm 3$ & $19 \pm 5$ \\
\hline Sintered Parts $(\mu \mathrm{m})$ & $40 \pm 5$ & $36 \pm 7$ \\
\hline \multicolumn{3}{|c|}{ Thickness } \\
\hline Mean thickness & MIM & CIM \\
\hline Green Parts $(\mathrm{mm})$ & $1.20 \pm 0.007$ & $1.16 \pm 0.006$ \\
\hline Sintered Parts $(\mathrm{mm})$ & $1.05 \pm 0.005$ & $0.92 \pm 0.004$ \\
\hline
\end{tabular}

